\title{
Análise Econômica da Prevenção e Controle do Cancro Cítrico no Estado de São Paulo
}

\author{
André Luis Ramos Sanches', Sílvia Helena Galvão de Miranda², \\ José Belasque Junior ${ }^{3}$ e Renato Beozzo Bassanezi ${ }^{4}$
}

Resumo: No presente trabalho estimou-se a relação benefício-custo de estratégias diferentes de controle do cancro cítrico (a prevenção e erradicação ou manejo) no estado de São Paulo, onde a citricultura é uma das principais culturas agrícolas em produção e emprego. $\mathrm{O}$ índice de talhões contaminados com cancro cítrico aumentou 893\% entre 2009 e 2012, logo após mudanças na legislação paulista de controle da doença, o que justifica a importância de analisar seus impactos econômicos, dado que o manejo da doença tem grande relevância econômica. Adota-se a Análise Benefício-Custo como instrumento para, ao identificar os custos e benefícios mais expressivos para o produtor rural, comparar a variação na produção e nos custos de produção. Para tanto, são simulados cenários de prevenção, controle ou manejo com expansão da doença, em um horizonte de 20 anos. Os resultados apontam vantagens econômicas em manter o cancro cítrico sob controle no estado de São Paulo, ou seja, sob níveis mais baixos de incidência, demonstrando que o manejo com expansão da doença no médio e longo prazos apresenta relação benefício-custo significativamente inferior à prevenção e controle da doença com erradicação rigorosa dos focos da doença.

Palavras-chaves: Citricultura, cancro cítrico, controle fitossanitário, análise benefício-custo.

Abstract: This paper aims to estimate the benefit-cost ratio of preventing,
managing the citrus canker in São Paulo State, where citrus is a major crop
production and jobs. The index of contaminated plots with citrus canker
percent between 2009 and 2012, right after changes in the State regulation to
disease, which justifies the importance of analyzing economic impacts. The
Analysis is applied, once the most relevant benefits and costs involved ar
1. Mestre em Economia Aplicada, ESALQ/USP. E-mail: andresanches@usp.br
2. Professora Doutora, ESALQ/USP. E-mail: shgdmira@usp.br
3. Professor Doutor, ESALQ/USP. E-mail: belasque@usp.br
4. Pesquisador Científico do Fundecitrus. E-mail: rbbassanezi@ fundecitrus.com.br 
compare the effects over production and costs of production in the farm level. Thus, scenarios are simulated of prevention of canker, control and management under an expansion rate, along a lifetime of 20 years. Results point economic advantages of holding the citrus canker under control in São Paulo, i.e., with low levels of contamination of orchards. Managing the disease only partially, in such a way to face its dissemination along the medium and long term presents a benefit-cost ratio significantly lower than that obtained in the scenarios of prevention and control of canker with a stricter eradication of outbreaks.

Key-words: Citrus sector, citrus canker, phytosanitary control, cost-benefit analysis.

Classificação JEL: Q1, Q14, Q18.

\section{Introdução}

O Brasil é o principal produtor mundial de laranja e responsável por cerca de $30 \%$ da produção da fruta e $53 \%$ de suco de laranja produzido mundialmente (FAO, 2012; NEVES et al., 2010). Além da relevância mundial, uma das características da citricultura brasileira é o elevado grau de concentração da produção entre os estados brasileiros, com destaque à superioridade no volume de produção do estado de São Paulo, responsável por $76 \%$ da produção nacional da fruta e $70 \%$ da área plantada com laranja no Brasil (IBGE, 2012).

A disseminação e potencial de impacto de pragas e doenças representam um risco relevante para a cadeia citrícola, pois além de comprometer a produtividade dos pomares, exigem investimentos em prevenção e controle e impactam diretamente na rentabilidade do citricultor. Segundo Miranda e Ximenes (2009), a citricultura no Brasil tem uma longa história de desafios nesse contexto, já que nas últimas décadas, algumas das mais importantes doenças introduzidas no país tiveram impacto nessa cultura: Tristeza (1937), Cancro Cítrico (1957), Pinta Preta (1980) e o Huanglongbing (2004).

No estado de São Paulo, principal parque citrícola mundial, ocorreu o expressivo aumento na disseminação do cancro cítrico entre os anos 2009 e 2012, considerado um dos principais problemas fitossanitários na cultura dos citros. O aumento na disseminação da doença ocorreu a partir de 2009, quando o governo paulista alterou a legislação de controle do cancro cítrico, e nos três anos seguintes a essa alteração, o índice de talhões contaminados com a doença apresentou um expressivo aumento de $893 \%$ no estado (FUNDECITRUS, 2014).

Ressalta-se que o cancro cítrico é considerado uma das doenças mais importantes na cultura dos citros, tendo como principal forma de controle, em áreas ainda indenes ou com baixíssimas incidências da doença, a prevenção da sua entrada no pomar e a erradicação das plantas contaminadas após sua introdução. A necessidade da erradicação gera um impacto econômico relevante no patrimônio do citricultor (GOTTWALD et al., 2001, 2002).

Análises de impactos econômicos de pragas e doenças são relevantes não só para evidenciar a importância das políticas de defesa agropecuária e contribuir com a identificação de prioridades, mas também para subsidiar as decisões não só dos produtores rurais, mas também da indústria que depende das matérias-primas e das indústrias da cadeia de suprimentos e desenvolvimento tecnológico em defensivos agrícolas.

Contudo, estudos dessa natureza são interdisciplinares e compreendem desafios adicionais como o de ajustar métodos utilizados comumente nas análises econômicas e estatísticas a problemas de natureza biológica. Embora ainda 
haja poucos registros na literatura econômica brasileira, há alguns estudos publicados nas áreas de fitopatologia e entomologia. No âmbito internacional, o desenvolvimento de análises dessa natureza tem surgido com mais frequência na literatura, inclusive com a aplicação de modelos mais sofisticados do que o aqui proposto, de Análise Benefício-Custo.

Assim, este trabalho teve como objetivo avaliar os benefícios e os custos da manutenção, ou não, da supressão do cancro cítrico no estado de São Paulo, comparando-a com a estratégia de manejo comumente adotada em áreas nas quais a doença é endêmica ou está em expansão.

\section{Fundamentação teórica}

\subsection{Análise de impacto econômico de doenças na agricultura}

Os impactos de pragas e doenças na agricultura e na pecuária podem ser significativos a ponto de inviabilizar o cultivo em determinada região produtora devido à redução de produtividade e altas taxas de investimento em prevenção e controle. Tal fato estimula a migração geográfica entre diferentes regiões produtoras, com possíveis impactos na renda, variação na quantidade de postos de trabalho, impactos sobre balança comercial quando afetam culturas exportadoras, entre outros efeitos não somente econômicos, mas também sociais e ambientais.

Como mencionado, Miranda e Ximenes (2009) apontam algumas das doenças e pragas que causaram prejuízos econômicos significativos para o Brasil. Estudos disponíveis na literatura nacional, em geral, apresentam estimativas dos prejuízos de pragas baseadas apenas na perda de produção.

Bento (2000) estimou a perda de produção no Brasil em 7,1\% por ano, decorrente de insetos, com base na perda média em cada cultura, a partir de registros e observações de campo realizadas por entomologistas em diversas regiões do Brasil e bancos de dados. Essa perda cor- respondia, na ocasião, a um prejuízo financeiro para a renda agrícola de cerca de US\$ 2,2 bilhões ao ano. Dentre as culturas, a produção da seringueira foi a mais afetada, seguida do caju, café e coco-da-baía; enquanto, em valores monetários, a cana-de-açúcar liderou o ranking de prejuízos anuais, com US\$ 467 milhões e perda de $10 \%$ da produção.

Em estudo mais recente e também com foco em danos causados por insetos na produção das principais culturas nacionais, estimou-se a soma de US\$12 bilhões anuais de prejuízos para a economia brasileira, dos quais US $\$ 1,6$ bilhão é decorrente de pragas exóticas (OLIVEIRA et al., 2012).

Uma abordagem que vem sendo aplicada no Brasil para tratar da avaliação de impacto da entrada e disseminação de pragas e mesmo para mensurar os benefícios econômicos das políticas sanitárias e fitossanitárias, é a da Análise Benefício-Custo (MIRANDA et al., 2010; BARRETTO et al., 2011; MIRANDA, BASSANEZI e ADAMI, 2011; OLIVEIRA, 2012). Uma das vantagens dessa metodologia é que é possível avaliar tanto os impactos com enfoque nos agentes individualmente como na economia do setor como um todo. Outro exemplo de desenvolvimento metodológico para tratar de temas econômicos relacionados à fitossanidade é o estudo recente de Costa e Guilhoto (2013) que analisa o impacto de novas tecnologias de diagnose do Huanglongbing, doença que atinge os citros também, usando uma análise de insumo-produto.

A Análise Benefício-Custo (ABC), que é a abordagem empregada no presente trabalho, é indicada especialmente para casos em que as dimensões de custo e de benefício de uma determinada ação não são claramente definidas, e com a finalidade de observar os fluxos financeiros e avaliar seus impactos econômicos. Sua utilização para auxílio na formulação de políticas públicas tem se tornado comum, já que identifica e quantifica os gastos e os benefícios das diversas alternativas de políticas, permitindo subsidiar a tomada de decisão. Nesse contexto, inclusive, a $A B C$ vem sendo adotada por países membros da Organização para Cooperação e 
Desenvolvimento Econômico na implantação de seus modelos de Análise de Impacto Regulatório (RIA - em inglês, Regulatory Impact Analysis).

Internacionalmente, há vários exemplos na literatura econômica, não só do uso da $\mathrm{ABC}$, mas também de outras metodologias associadas a analisar problemas fitossanitários. Macleod (2006) cita Rautapaa (1984) que examina benefícios e custos de manter a Finlândia livre da Mosca Minadora (Liriomyza trifolii) em crisântemos. Há registros, ainda, da utilização da metodologia ABC aliada a instrumentos econométricos. A ABC foi aplicada nos Estados Unidos para subsidiar as decisões do USDA (Departamento de Agricultura dos Estados Unidos) em casos envolvendo o comércio internacional de produtos agropecuários (CALVIN e KRISSOFF, 1998).

$\mathrm{Na}$ literatura existem alguns trabalhos que avaliam economicamente o risco fitossanitário específico na cultura dos citros. Hodges and Rahmani (2009) estimam o impacto econômico do Huanglongbing na indústria citrícola do estado da Flórida (EUA); Muraro e Spreen (2006) discutem o impacto de doenças na cultura dos citros e a consequente variação na oferta de suco processado no estado da Florida; Muraro e Malugem (2006) relacionam o preço da terra com diferentes níveis de disseminação do cancro cítrico e Huanglongbing, com a rentabilidade dos pomares e o preço da laranja na Florida.

\subsection{Importância do caso do cancro cítrico}

Dentre outras pragas e doenças, a citricultura paulista está sujeita ao cancro cítrico, doença incitada pela bactéria Xanthomonas citri subsp. citri (Xcc), considerado um dos principais problemas fitossanitários da cultura dos citros (KOIZUMI, 1985; GOTTWALD et al., 2001, 2002). Não há métodos curativos para essa doença e as estratégias de controle comumente utilizadas dependem da região geográfica, da legislação vigente e do destino da produção. Em razão do cancro cítrico não estar presente em todas as regiões produtores de cítricos do mundo, há restrições quarentenárias limitantes para o comércio de fru- tas cítricas de áreas nas quais Xcc está presente (FUNDECITRUS, 2014).

A primeira detecção desse patógeno no Brasil ocorreu em 1957 no estado de São Paulo e posteriormente foi encontrada também nos estados do Paraná, Santa Catarina, Rio Grande do Sul, Mato Grosso, Mato Grosso do Sul, Minas Gerais e Roraima (AMARAL, 1957).

O cancro cítrico tem grande relevância econômica, pois reduz a produtividade do pomar, provoca desfolha das plantas contaminadas e a queda prematura nos frutos, além de restringir o uso dos cultivares altamente suscetíveis à doença, as chamadas variedades precoces (GOTTWALD et al., 2001, 2002; BEHLAU et al., 2007, 2008). Segundo Neves et al. (2010), o parque citrícola paulista é composto por $20 \%$ de variedades precoces, portanto sua suscetibilidade deve gerar um custo significativo no estado.

Desde 1957 os governos federal e estadual possuem legislações específicas referentes ao cancro cítrico. Especificamente para o estado de São Paulo, entre 2009 e 2013, os focos de cancro cítrico deveriam ser, obrigatoriamente, eliminados pela queima das plantas sintomáticas e das demais contidas num raio de 30 metros a partir das plantas sintomáticas, segundo a legislação da época (SÃO PAULO, 2009). Essa orientação foi estabelecida pela Resolução SAA n. 43, de 25/06/2009, que alterou a obrigatoriedade, anteriormente vigente no estado, de se erradicar todas as plantas dos talhões que apresentassem mais que $0,5 \%$ de plantas sintomáticas, mantendo apenas a obrigatoriedade de erradicar apenas as plantas sintomáticas e as demais contidas num raio de 30 metros.

Além do menor rigor da legislação de erradicação de plantas com cancro cítrico, também a partir do final de 2009, houve alteração na operacionalização da política de defesa citrícola no estado, tendo em vista que o convênio antes vigente entre a Secretaria de Agricultura e Abastecimento do Estado de São Paulo (SAA) e o Fundecitrus não foi renovado e esse último deixou de ter como atribuição o apoio à inspeção e erradicação das plantas doentes, fato que contribuiu para a expansão da doença. 
Mesmo com o aumento acentuado na disseminação da doença, o controle de cancro cítrico foi novamente abrandado no estado de São Paulo. A partir da Resolução n. 147, de 01/11/2013, deixou de ser obrigatória a erradicação das plantas contidas no raio de 30 metros e passou-se a adotar apenas a eliminação das plantas sintomáticas. As plantas contidas no raio de 30 metros, a partir da planta sintomática, devem ser pulverizadas com bactericidas cúpricos, repetindo a pulverização a cada brotação das plantas. O citricultor deve realizar também, no mínimo, uma vistoria trimestral em todas as plantas de citros da propriedade, com o objetivo de identificar e eliminar plantas que apresentem sintomas de cancro cítrico (SÃO PAULO, 2013; FUNDECITRUS, 2014).

Após as mudanças citadas na política de defesa fitossanitária, o status de controle do cancro cítrico em São Paulo saiu de uma situação de supressão com níveis de incidência baixos e estáveis para uma situação de epidemia. Entre 2000 e 2008 o índice de talhões contaminados pela doença variou entre $0,08 \%$ e $0,27 \%$ dos talhões do parque citrícola paulista, segundo estimativas do Fundecitrus. Porém, a partir de 2009, a doença passou a apresentar expansão acelerada no estado, passando de 0,14\% em 2009 para 0,42\%, 0,99\% e 1,39\% dos talhões contaminados, nos anos de 2010, 2011 e 2012 respectivamente (Figura 1).

Conforme exposto na Figura 1, verifica-se que a citricultura paulista enfrentou, em 2012, o maior nível de disseminação do cancro cítrico desde a primeira detecção desse patógeno no Brasil (FUNDECITRUS, 2014). Diante do histórico de potencial de prejuízos desta doença e da recente disseminação em São Paulo, torna-se evidente a relevância das decisões que os citricultores estão tomando atualmente quanto às ações preventivas ou de controle do cancro cítrico.

\section{Metodologia}

Para identificar e delimitar os impactos econômicos da disseminação do cancro cítrico em São Paulo foram estabelecidos cenários que permitam comparar as situações de prevenção da doença, manutenção de seu índice de contaminação sob controle e por fim, doença em expansão. A partir da análise de fluxos de caixa para a citricultura paulista em cada cenário, calculou-se a sua relação benefício-custo, para um horizonte de 20 anos, a partir de 2009.

Parte-se do pressuposto que o cancro cítrico compromete a produtividade da árvore $\mathrm{e}$ aumenta o custo de produção agrícola, sendo esses os dois impactos mais significativos para $o$ produtor rural, e, por isso, foco deste estudo. Nos cenários simulados foram considerados diferentes níveis de disseminação da doença, produtividade das plantas contaminadas, árvores erradicadas, número de inspeções, quantidade de aplicações

Figura 1. Série histórica do Índice de talhões contaminados (\%) por cancro cítrico no estado de São Paulo (2000-2012)

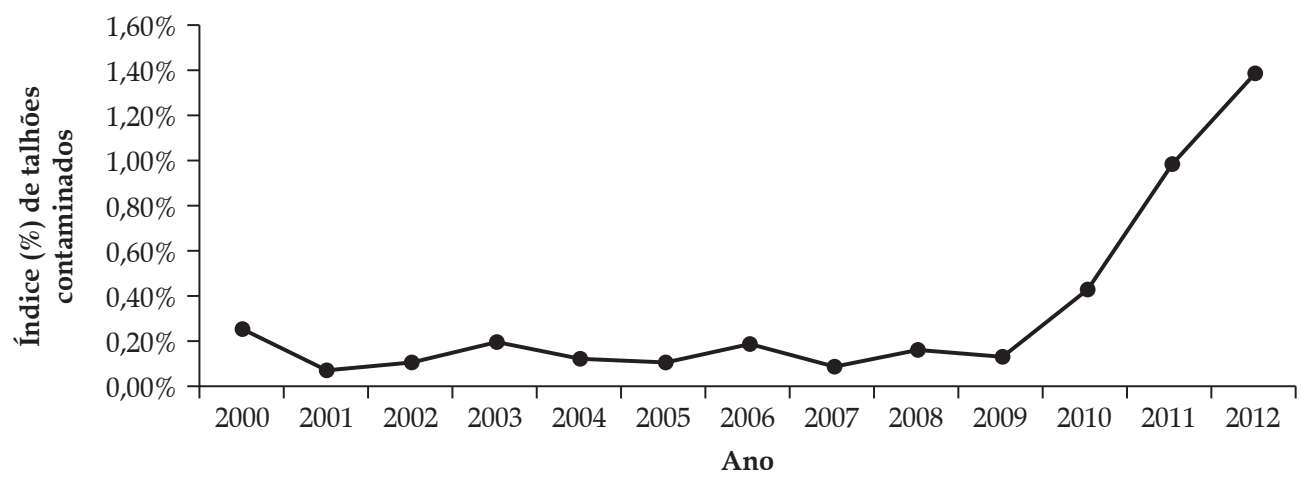

Fonte: Fundecitrus (2014). 


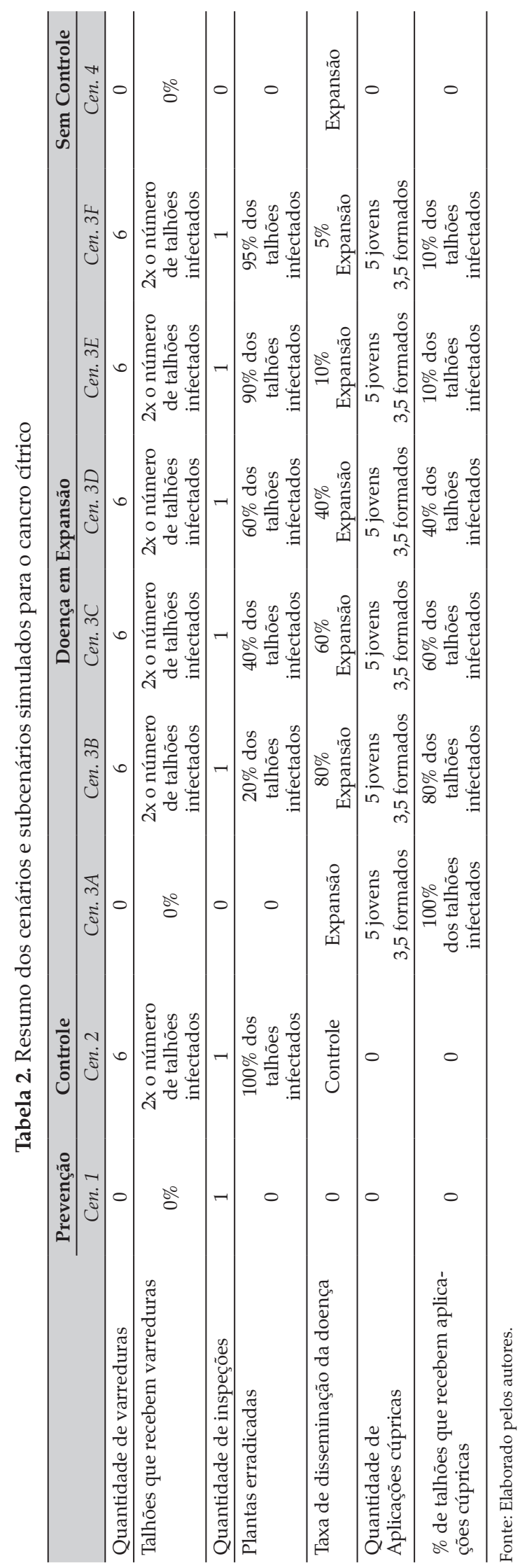


cúpricas e de percentual de replantio das plantas eliminadas. Os custos são avaliados com base nos fluxos de caixa dos produtores nos diferentes cenários, considerando além do custo de produção, em destaque os custos referentes ao manejo do cancro compreendendo as despesas com aplicações cúpricas e com as inspeções para o cancro cítrico (esse elemento será explicado a seguir) e as despesas adicionais com a eliminação das plantas e replantio de novas árvores sadias.

Os benefícios, por sua vez, são estimados pela valoração das perdas evitadas na receita bruta dos produtores rurais, ao adotar as medidas de prevenção e controle, ou seja, perdas evitadas com a redução da produtividade. As perdas evitadas são medidas pela diferença entre a produtividade (e produção) nos cenários com controle do cancro e a produtividade nos cenários sem controle (ou seja, assumindo expansão da doença).

Os prejuízos potenciais estimados são imputados como perdas evitadas ou benefícios, da ação de prevenção ou de controle da doença. A comparação entre essas perdas evitadas, o benefício de manter plantas livres da doença contendo o crescimento do índice de contaminação de talhões, e o diferencial de custos das ações tomadas pelos produtores, resulta nos benefícios líquidos.

\subsection{Cenários}

Os cenários analisados neste estudo estão resumidos na Tabela 1. No Cenário 1 - Prevenção - considera-se que ao custo total da cultura é adicionado o custo de uma inspeção exclusiva para o cancro cítrico ao ano, em todo o parque citrícola ${ }^{5}$.

5. Mesmo que as inspeções de campo não sejam um custo específico ao controle do cancro cítrico, pela possibilidade de identificar um conjunto de pragas, nas simulações optou-se por considerar o custo das inspeções como custo de prevenção e controle do cancro, por esse ser considerado o de maior peso (em termos financeiros) referente à prevenção em áreas livres da doença. Com base na experiência de campo adquirida pelo Fundecitrus, sabe-se que as inspeções de cancro cítrico são exclusivas para cancro cítrico em regiões com maior pressão de disseminação da doença, pois exigem uma inspeção diferente, mais lenta e mais rigorosa que as inspeções de rotina para outras pragas.
A hipótese é de que o estado mantenha-se livre da doença ao longo dos 20 anos de simulação.

No Cenário 2 - Controle - adota-se que o índice de disseminação da doença permanece constante em $0,15 \%$ dos talhões, que é a média do índice observado no estado entre os anos de 2000 e 2008. Neste cenário, assume-se que se erradiquem todas as plantas existentes nos talhões contaminados, e não somente as plantas detectadas e as demais existentes num raio de 30 metros ao redor de cada planta ${ }^{6}$. Quanto às inspeções, considera-se a realização de seis varreduras em $0,3 \%$ das plantas do parque ao ano (o dobro do índice de talhões contaminados) e de uma única inspeção ao ano no restante do parque, sob responsabilidade do próprio produtor.

Denomina-se varredura a inspeção exclusiva para o cancro cítrico em áreas próximas de focos de plantas sintomáticas, que exigem inspeções com um elevado grau de detalhamento e eficiência, razão pela qual se adota como rendimento médio, apenas 200/plantas/dia/homem. Já nas denominadas inspeções (de forma genérica, que não varreduras), o rendimento do inspetor em áreas sem histórico, ou distantes de focos de plantas sintomáticas, é de 700 plantas/dia/homem. O rendimento das varreduras e das inspeções foi definido com base na experiência dos técnicos do Fundecitrus que trabalham diretamente no controle do cancro cítrico.

Nos Cenários 3 - Doença em Expansão assume-se que a doença continua se disseminando a taxas geométricas, em ritmo semelhante ao que foi observado entre os anos de 2009 e 2011, no estado de São Paulo. Em seus subcenários, assume-se que um percentual do parque citrícola realiza a supressão da doença de forma rigorosa, com inspeções e erradicações dos talhões, enquanto o restante faz a opção da convivência com a doença.

6. Considera-se erradicação de todas as plantas do talhão, por uma questão de facilidade operacional, já que a legislação vigente no estado de São Paulo no período em que a doença foi considerada sob controle determinava a obrigatoriedade de erradicar todas as plantas no raio de 30 metros a partir da planta foco. 
Nos subcenários 3 o percentual de plantas contaminadas que não é erradicado recebe aplicações cúpricas com o objetivo de reduzir o impacto na produtividade das plantas ${ }^{7}$. Os subcenários 3 variam quanto ao percentual dos talhões infectados que são erradicados. O objetivo dos subcenários 3 é simular situações resultantes da falta de uniformidade na estratégia de controle do cancro cítrico no estado de São Paulo, onde um percentual do parque citrícola realiza a supressão, por meio de inspeções frequentes e erradicação de talhões contaminados, e outro percentual do parque citrícola faz a opção pelo manejo com a doença, não erradicando as plantas contaminadas e promovendo aplicações cúpricas em seus talhões. Pressupõe-se que a mesma proporção de erradicação de talhões contaminados prevalece para a redução na taxa de avanço da doença nos subcenários 3, ou seja, se $20 \%$ dos talhões contaminados são erradicados, a taxa de aumento da doença anual é reduzida no mesmo percentual. Assim, os subcenários 3A, 3B, 3C, 3D, 3E e 3F referem-se à simulação de erradicação de $0 \%, 20 \%$, $40 \%, 60 \%, 90 \%$ e $95 \%$ dos talhões contaminados e, respectivamente, as mesmas proporções de redução da taxa de aumento da doença.

Para todos estes subcenários, os talhões contaminados e não erradicados recebem cinco aplicações cúpricas em plantas com menos de cinco anos de idade, e 3,5 aplicações ${ }^{8}$ em plantas com mais de cinco anos de idade, por ano. Realizam-se seis varreduras anuais no dobro de talhões contaminados e uma inspeção anual para o restante do parque citrícola, com exceção do subcenário 3A, no qual apenas são feitas as aplicações cúpricas, mas não há erradicação de plantas, nem despesas com inspeções e varreduras.

7. Aplicações cúpricas em plantas contaminadas com o cancro cítrico são a principal forma de reduzir as perdas na produtividade das plantas em áreas de manejo da doença no Brasil e em outros países da América (BEHLAU et al., 2008, 2010).

8. A escolha por 3,5 aplicações deu-se após verificar, junto a produtores e especialistas da área, que na situação de prevenção com histórico da doença realizam-se de três a quatro aplicações cúpricas nas plantas com mais de cinco anos de idade, chegando à média de 3,5 aplicações.
O Cenário 4 - Sem Controle - simula a situação extrema em que a doença segue em expansão e nenhum tipo de controle é realizado. O local onde as plantas não são inspecionadas, os talhões contaminados não são erradicados e não recebem tratamento químico. No cálculo da produção e receita bruta da cultura, assume-se a redução na produtividade das plantas contaminadas e tratadas, ou seja, que não foram erradicadas, e recebem tratamento químico, com aplicações cúpricas.

$\mathrm{Na}$ totalidade dos cenários simulados foi adotada a pressuposição de que todas as plantas sadias do parque citrícola apresentem a mesma produtividade, condicionada à idade da planta, conforme mostrado na Tabela 2.

Como foi dito acima, plantas contaminadas pelo cancro cítrico quando não tratadas com aplicações cúpricas sofrem redução na produtividade, assumindo-se uma perda média anual de $20 \%$ na produtividade, que varia de acordo com a idade da planta. Plantas contaminadas pelo cancro cítrico, quando tratadas quimicamente com aplicações cúpricas independente da idade da planta, sofrem redução média de $5 \%$ na produtividade. As proporções de redução da produtividade foram definidas com base no conhecimento de episódios da doença no estado de São Paulo, na convivência do estado do Paraná com o cancro e literatura da área (BEHLAU et al., 2007, 2008).

Outra pressuposição para a modelagem consiste em considerar $100 \%$ de sucesso nos replantios, mantendo-se, assim, o stand dos pomares paulistas em todos os cenários simulados.

\subsection{Dados utilizados na simulação}

Neste trabalho, foram utilizados dados do Fundecitrus para número de plantas de citros no estado de São Paulo e sua distribuição em categorias por idade, assim como para o índice de contaminação dos talhões e produtividade. Considera-se que o parque citrícola paulista é composto por 217.670.262 árvores, distribuídas em 93.490 talhões (FUNDECITRUS, 2014). Por simplificação, adotou-se que todos os talhões do parque citrícola paulista apresentam o mesmo 
Tabela 3. Produtividade média na produção de laranjas por pé, em São Paulo

\begin{tabular}{cccc}
\hline Idade & $\begin{array}{c}\text { Produtividade média } \\
\text { na produção de laranjas por pé } \\
\text { (caixas*/pé) }\end{array}$ & $\begin{array}{c}\text { Percentual de redução na } \\
\text { produtividade de plantas contaminadas } \\
\text { e não tratadas } \mathbf{\%})\end{array}$ & $\begin{array}{c}\text { Taxa natural de renovação } \\
\text { dos pomares de } \mathbf{0} \text { a 20 anos } \\
(\%)\end{array}$ \\
\hline 1 & 0,00 & 50 & 0,04 \\
2 & 0,00 & 50 & 0,06 \\
3 & 0,74 & 50 & 0,08 \\
4 & 1,00 & 50 & 0,1 \\
5 & 1,23 & 50 & 0,2 \\
6 & 1,44 & 40 & 0,3 \\
7 & 1,63 & 40 & 0,4 \\
8 & 1,80 & 30 & 0,5 \\
9 & 1,94 & 30 & 0,6 \\
10 & 2,06 & 20 & 0,7 \\
11 & 2,17 & 20 & 0,8 \\
12 & 2,24 & 15 & 0,9 \\
13 & 2,30 & 15 & 1 \\
14 & 2,33 & 10 & 1,1 \\
15 & 2,35 & 10 & 1,2 \\
16 & 2,34 & 10 & 1,3 \\
17 & 2,30 & 10 & 1,4 \\
19 & 2,25 & 10 & 1,5 \\
\end{tabular}

Fonte: Fundecitrus (2014).

número de plantas, 2.328 pés, obtido pela divisão do total de pés no estado pelo número de talhões.

Assume-se que todos os pomares de laranja doce do estado tenham a mesma suscetibilidade ao cancro cítrico, desconsiderando as diferenças quanto à idade, variedades e outros fatores que podem predispor as plantas à infecção pelo patógeno.

Para a projeção do número de árvores de citros do estado ao longo dos anos de simulação, adota-se uma taxa natural de renovação dos pomares, também apresentada na tabela 2 . A taxa natural é justificada pela presença de outras pragas e doenças nos pomares, assumindo que $100 \%$ das plantas com 20 anos de idade são eliminadas. Não se consideram as taxas de erradicação devidas ao Huanglongbing (ou Greening), a fim de isolar apenas os efeitos do potencial avanço do cancro cítrico no estado.

A quantidade de árvores erradicadas por causa do cancro cítrico é definida com base na taxa de disseminação da doença. Ao projetar o percentual de talhões contaminados ao longo dos 20 analisados é possível definir o número de plantas erradicadas, pressupondo que todos os talhões no estado de São Paulo apresentem o mesmo número de árvores. As plantas erradicadas pelo cancro cítrico são replantadas após dois anos de seu arranquio, medida determinada pela legislação federal.

Nos subcenários Doença em Expansão pressupõe-se que as curvas de progresso da doença, para cada cenário, seguem o modelo epidemiológico de Gompertz, calculado com base nos seguintes quesitos: a) progresso da doença nos três anos seguintes à mudança na legislação paulista de erradicação do cancro cítrico; e b) proporção de talhões erradicados em cada um dos subcenários descritos para a Doença em Expansão.

Uma vez simuladas as taxas de avanço do cancro cítrico em cada um dos cenários e adotadas uma respectiva taxa de erradicação, essas são aplicadas sobre o número de árvores citrícolas do estado para projetar o número anual de plan- 
Figura 2. Projeção da incidência da doença, em percentual de talhões, para o estado de São Paulo através da curva de Gompertz, na situação sem controle (2009-2030)

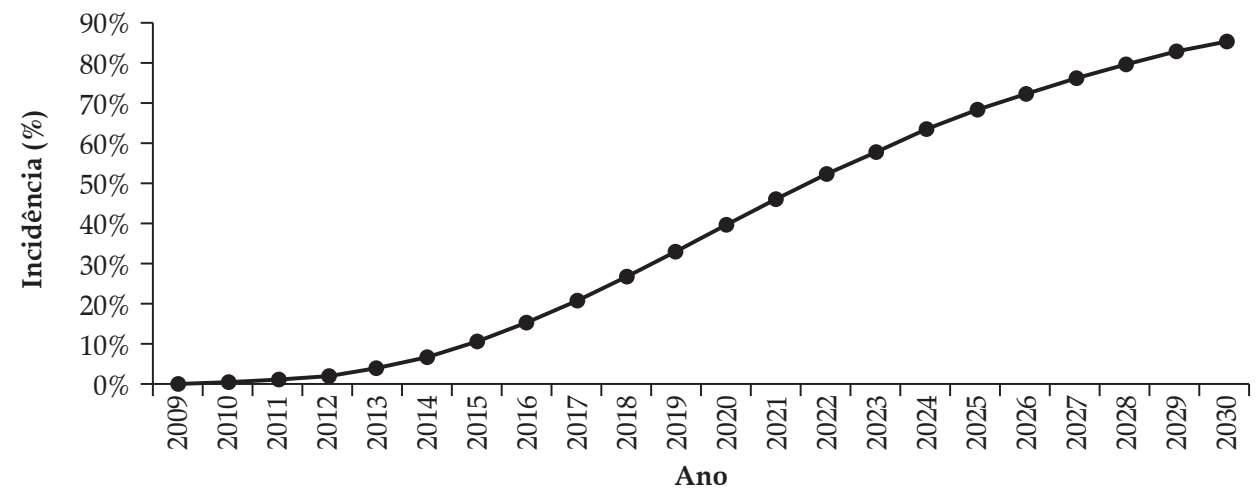

Fonte: Resultados da pesquisa.

tas nos pomares paulistas ao longo do tempo. Com base neste número e na produtividade, já apresentada, calcula-se a produção em caixas de laranja para os diferentes cenários.

Em relação aos custos, a partir de consultas a empresas especializadas em inspeção em citros, assim como a profissionais independentes que atuam na área, definiu-se como $\mathrm{R} \$ 60,00$ o custo médio do dia/homem, para inspeções destinadas a detecção de plantas com sintomas de cancro cítrico.

Para as aplicações cúpricas considerou-se o uso de 2,5 $\mathrm{Kg}$ de hidróxido de cobre (Kocide WDG) para cada 2000 litros de calda, volume suficiente para a pulverização de 350 plantas com mais de três anos de idade e cerca de 500 plantas com menos de três anos de idade. Com base na série histórica de preços do produto comercial Kocide WDG, entre março de 2002 e julho de 2012, divulgada pelo Instituto de Economia Agrícola (IEA), adotou-se a média de R\$ 266,80/ $10 \mathrm{Kg}$ do produto, expressos em Reais de julho de $2012^{9}$.

Para o cálculo de custos de produção dos pomares, adotou-se como referência o custo de produção médio para o estado de São Paulo, apresentado pela Companhia Nacional de

9. O Índice Nacional de Preços ao Consumidor (INPC) é usado como deflator no cálculo do valor presente de todos os valores monetários considerados nas simulações.
Abastecimento (Conab), de $\mathrm{R} \$ 13,94$ por planta, com mais de dois anos. A esses custos foram acrescidos os custos específicos para controle do cancro cítrico, que são detalhados ao longo do trabalho para cada uma das situações simuladas (cenários).

Para plantas de 0 a 2 anos, o custo de produção (implantação do pomar) é do CEPEA/ESALQ, no montante de $\mathrm{R} \$ 26,72$ para os três primeiros anos, sendo assim distribuídos: $\mathrm{R} \$ 16,81 /$ planta no ano do plantio, $\mathrm{R} \$ 5,19 /$ planta e $\mathrm{R} \$ 4,12 /$ planta, nos dois anos subsequentes.

Em todos os cenários que simulam erradicação de plantas devido ao cancro cítrico, considera-se como parte dos custos da doença o valor das plantas erradicadas, assim como o custo de erradicá-las e replantá-las. Para tanto, com base em consulta a técnicos especializados na produção de citros, definiu-se como R 23,50 o valor médio das plantas erradicadas, em reais de julho de 2012, incluídos nesse valor os custos referentes à erradicação e replantio.

Uma vez projetada a evolução do pomar no estado e da doença, foram calculadas as caixas produzidas ao longo de 20 anos e valoradas utilizando-se um preço médio para a laranja. Com base nos preços médios da caixa de laranja posta na indústria paulista (sem contrato) divulgados pelo CEPEA/ESALQ, e fazendo o deflacionamento pelo INCP para valores reais de junho de 
2012, definiu-se como média de preços reais entre janeiro de 1995 e julho de 2012, o valor de $\mathrm{R} \$ 10,50$ por caixa.

Para fins de comparação e análise de sensibilidade das relações benefício-custo aos preços, também foram simuladas situações com preços reais de $R$ \$ 3,30 e $R$ \$ 21,10 por caixa, que representam os patamares inferior e superior verificados no período de janeiro de 1995 a julho de 2012. O preço da caixa de laranja, assim como todos os outros valores monetários, é mantido constante em termos reais ao longo da projeção. Após projetar os valores monetários ao longo do horizonte de simulação, estes foram trazidos a valor presente considerando uma taxa de desconto constante de $6 \%$ ao ano, definida com base na taxa de juros de longo prazo concebida pelo BNDES, entre os anos de 2007 e 2012.

\section{Resultados}

Os resultados encontrados indicam que a estratégia de controle do cancro cítrico causa variações relevantes no custo de produção dos citricultores paulistas a médio e longo prazos. Medidas de prevenção e manejo da doença como inspeções dos pomares, erradicação e replantio de plantas, e tratamento químico com aplicações cúpricas apresentam impacto menor nos custos acumulados quanto maior for o número de plantas recebendo a mesma estratégia de convívio ou supressão da doença.

Os resultados da simulação, com relação à quantidade de caixas produzidas, valor presente da produção e valor presente dos custos estão sintetizados na tabela 3 , no acumulado de 5, 10, 15 e 20 anos de projeção.

A produção esperada em caixas de laranja para o acumulado dos 20 anos, na ausência da doença, seria 7,38 bilhões de caixas de laranja no
Cenário 1 (prevenção). Essa produção se reduz para cerca de 6,77 bilhões de caixas no Cenário 4 (sem controle) em que a doença segue em expansão e as plantas doentes no campo não são eliminadas ou pulverizadas com cúprico.

No Cenário 2 (controle), em que a taxa de incidência da doença permanece constante ao longo dos 20 anos (ou seja, sob controle), a produção esperada é aproximadamente 7,35 bilhões de caixas. Os resultados indicam que se houver uma taxa de erradicação que permita manter a doença sob uma taxa de incidência constante e baixa ao longo dos 20 anos, à semelhança do que ocorreu ao longo dos anos 2000, a produção acumulada praticamente se mantém em relação ao cenário sem a doença.

No Cenário 3, em que a doença se expande a taxas crescentes, observa-se que a quantidade produzida acumulada nos 20 anos varia diretamente com o percentual de talhões erradicados, evidenciando que a eliminação das plantas doentes que consistem em fonte de inoculo é importante para se manter o nível de produção. $\mathrm{O}$ cenário 3A é uma exceção a esta lógica, pois não se erradicam as plantas com cancro, mas todos os talhões são tratados curativamente com o objetivo de manter o volume de produção, nos moldes do que é realizado atualmente nas regiões que convivem com a doença.

$\mathrm{O}$ resultado encontrado demonstra que a diferença de produção entre o Cenário 1 (prevenção) e o Cenário 4 (sem controle) no acumulado de 5, 10, 15 e 20 aumenta significativamente ao longo dos anos, passando de 17,8 para 113,27, 322,78 e 611,74 milhões de caixas respectivamente. Cabe lembrar que se assumiu a hipótese de que há $100 \%$ de sucesso na reposição de plantas eliminadas pela doença, o que contribui para que as diferenças na produção total não sejam maiores, mas por outro lado eleva os custos. 
Tabela 1. Quantidade de caixas $(40,8 \mathrm{Kg})$, valor presente do custo total, subdividido em custo de produção e custo com manejo do cancro, acumulado para 5, 10, 15 e 20 anos de projeção. Estado de São Paulo, 2011 a 2030

\begin{tabular}{|c|c|c|c|c|}
\hline Cenário / tempo (anos) & 5 anos & 10 anos & 15 anos & 20 anos \\
\hline \multicolumn{5}{|l|}{ Cenário 1 - prevenção } \\
\hline Milhões de caixas $(40,8 \mathrm{Kg})$ & $2.179,38$ & $3.936,91$ & $5.679,82$ & $7.382,59$ \\
\hline VP do custo total (milhões de R\$) & $18.765,80$ & $29.894,17$ & $38.223,68$ & $44.377,50$ \\
\hline VP do custo produção (milhões de R\$) & $18.668,55$ & $29.738,19$ & $38.023,82$ & $44.144,84$ \\
\hline VP do custo de manejo do cancro (milhões de R\$) & 97,25 & 155,98 & 199,86 & 232,66 \\
\hline \multicolumn{5}{|l|}{ Cenário 2 - controle } \\
\hline Milhões de caixas $(40,8 \mathrm{Kg})$ & $2.171,55$ & $3.915,92$ & $5.648,70$ & $7.347,94$ \\
\hline VP do custo total (milhões de R\$) & $18.771,70$ & $29.895,02$ & $38.228,19$ & $44.392,00$ \\
\hline VP do custo produção (milhões de R\$) & $18.634,60$ & $29.675,12$ & $37.946,40$ & $44.063,94$ \\
\hline VP do custo de manejo do cancro (milhões de R\$) & 137,10 & 219,90 & 281,79 & 328,06 \\
\hline \multicolumn{5}{|c|}{ Cenário 3A - controle parcial com taxa crescente de expansão } \\
\hline Milhões de caixas $(40,8 \mathrm{Kg})$ & $2.174,91$ & $3.908,67$ & $5.601,31$ & $7.236,25$ \\
\hline VP do custo total (milhões de R\$) & $18.698,37$ & $29.893,89$ & $38.382,69$ & $44.714,82$ \\
\hline VP do custo produção (milhões de R\$) & $18.668,55$ & $29.738,19$ & $38.023,82$ & $44.144,84$ \\
\hline VP do custo de manejo do cancro (milhões de R\$) & 29,82 & 155,70 & 358,87 & 569,98 \\
\hline \multicolumn{5}{|c|}{ Cenário 3B - controle parcial com taxa crescente de expansão } \\
\hline Milhões de caixas $(40,8 \mathrm{Kg})$ & $2.161,51$ & $3.789,83$ & $5.217,89$ & $6.497,98$ \\
\hline VP do custo total (milhões de R\$) & $18.951,47$ & $30.508,57$ & $39.325,09$ & $45.982,71$ \\
\hline VP do custo produção (milhões de R\$) & $18.599,68$ & $29.307,03$ & $36.982,08$ & $42.543,35$ \\
\hline VP do custo de manejo do cancro (milhões de R\$) & 351,80 & $1.201,53$ & $2.343,01$ & $3.439,36$ \\
\hline \multicolumn{5}{|c|}{ Cenário 3C - controle parcial com taxa crescente de expansão } \\
\hline Milhões de caixas $(40,8 \mathrm{Kg})$ & $2.155,08$ & $3.778,42$ & $5.247,87$ & $6.622,63$ \\
\hline VP do custo total (milhões de R\$) & $18.920,57$ & $30.250,65$ & $38.759,42$ & $45.128,17$ \\
\hline VP do custo produção (milhões de R\$) & $18.566,87$ & $29.254,04$ & $37.013,56$ & $42.705,73$ \\
\hline VP do custo de manejo do cancro (milhões de R\$) & 353,70 & 996,61 & $1.745,87$ & $2.422,44$ \\
\hline \multicolumn{5}{|c|}{ Cenário 3D - controle parcial com taxa crescente de expansão } \\
\hline Milhões de caixas $(40,8 \mathrm{Kg})$ & $2.153,31$ & $3.807,55$ & $5.381,44$ & $6.912,11$ \\
\hline VP do custo total (milhões de $\mathrm{R} \$$ ) & $18.920,57$ & $30.250,65$ & $38.759,42$ & $45.128,17$ \\
\hline VP do custo produção (milhões de R\$) & $18.557,46$ & $29.342,68$ & $37.319,92$ & $43.228,78$ \\
\hline VP do custo de manejo do cancro (milhões de R\$) & 318,83 & 731,40 & $1.144,39$ & $1.493,72$ \\
\hline \multicolumn{5}{|c|}{ Cenário $3 \mathrm{E}$ - controle parcial com taxa crescente de expansão } \\
\hline Milhões de caixas $(40,8 \mathrm{Kg})$ & $2.155,66$ & $3.862,66$ & $5.554,90$ & $7.226,65$ \\
\hline VP do custo total (milhões de $\mathrm{R} \$$ ) & $18.814,55$ & $29.942,43$ & $38.291,58$ & $44.488,40$ \\
\hline VP do custo produção (milhões de R\$) & $18.567,46$ & $29.515,63$ & $37.722,02$ & $43.809,39$ \\
\hline VP do custo de manejo do cancro (milhões de R\$) & 247,09 & 426,80 & 569,57 & 679,01 \\
\hline \multicolumn{5}{|c|}{ Cenário 3F - controle parcial com taxa crescente de expansão } \\
\hline Milhões de caixas $(40,8 \mathrm{Kg})$ & $2.156,34$ & $3.870,29$ & $5.574,27$ & $7.257,12$ \\
\hline VP do custo total (milhões de R\$) & $18.806,41$ & $29.931,71$ & $38.279,38$ & $44.470,62$ \\
\hline VP do custo produção (milhões de R\$) & $18.570,46$ & $29.539,37$ & $37.766,68$ & $43.866,85$ \\
\hline VP do custo de manejo do cancro (milhões de R\$) & 235,96 & 392,34 & 512,71 & 603,78 \\
\hline \multicolumn{5}{|c|}{ Cenário 4 - sem controle com taxa crescente de expansão } \\
\hline Milhões de caixas $(40,8 \mathrm{Kg})$ & $2.161,58$ & $3.823,63$ & $5.357,03$ & $6.770,85$ \\
\hline VP do custo total (milhões de R\$) & $18.668,55$ & $29.738,19$ & $38.023,82$ & $44.144,84$ \\
\hline VP do custo produção (milhões de R\$) & $18.668,55$ & $29.738,19$ & $38.023,82$ & $44.144,84$ \\
\hline VP do custo de manejo do cancro (milhões de R\$) & 0,00 & 0,00 & 0,00 & 0,00 \\
\hline
\end{tabular}

Fonte: Resultados da Pesquisa. 
A diferença significativa entre a quantidade produzida entre o Cenário 1 (prevenção) e o Cenário 4 (sem controle) corrobora a importância de evitar a disseminação do cancro cítrico nas regiões onde a doença ainda não está presente. Vale a pena ressaltar que, segundo o último levantamento realizado pelo Fundecitrus em 2012, cerca de $98 \%$ do parque citrícola paulista estava livre da doença e o corrente abrandamento no seu controle exigirá a adoção de medidas de manejo da doença no médio e longo prazos.

Com relação aos custos de manejo do cancro cítrico nas simulações, citado anteriormente, foram considerados os custos despendidos com as inspeções, a eliminação e replantio das plantas e o controle químico com aplicações cúpricas. Ressalta-se que os custos referentes ao controle e manejo da doença estão subestimados, pois a experiência de regióes que convivem com o cancro cítrico, como no estado do Paraná, demonstra que, na presença da doença, outros custos também são relevantes. É o caso do controle químico da larva minadora que deve ser intensificado e a utilização de quebra-ventos como uma barreira física que visa a atenuar também a sua disseminação. Ambos os custos foram desconsiderados no presente estudo. No caso do quebra-vento estima-se que além de custo e tempo para sua implementação, o mesmo gera uma perda de $10 \%$ da área plantada do pomar, ou seja, no quadro endêmico da doença, é razoável considerar uma perda similar ou próxima a esse percentual também no volume de produção.

Outro custo que não foi considerado nos cenários, e que pode assumir grande relevância no parque citrícola paulista, refere-se à necessidade de replantar parte expressiva das plantas devido à susceptibilidade das variedades cultivadas no parque citrícola paulista, as chamadas variedades precoces altamente suscetíveis ao cancro cítrico, diferente das variedades mais frequentemente cultivadas no Paraná. Segundo dados do Fundecitrus (2012), cerca de 10\% dos pés de laranja de São Paulo deverão ser substituídos na situação de convívio com o cancro, por ser este o percentual de plantas de varieda- des suscetíveis ao cancro (como a Hamlin) nesse estado.

Com relação aos custos de manejo do cancro, existem diferenças expressivas no resultado das simulações entre as situações de prevenção (Cenário 1), controle (Cenário 2) e doença em expansão (Cenário 3). Como era de se esperar, a situação de prevenção é a que apresenta menor custo de manejo dentre todas as situações simuladas, pois não é necessário erradicar plantas, ou realizar tratamento químico nas plantas, o que demonstra os benefícios financeiros em manter um parque citrícola livre da doença.

No Cenário 2 (controle), que a disseminação é mantida no mesmo nível médio do observado nos anos 2000, os custos são levemente superiores aos custos do cenário 1 (prevenção), mas expressivamente inferiores aos encontrados nas situações em que um percentual do parque realiza o controle e convive com a doença (subcenários 3B, 3C, 3D, 3E e 3F).

O menor custo do cenário controle frente às situações em que um percentual de parque citrícola maneja e outro percentual erradica a doença, sinaliza os benefícios em termos de custos de produção em manter a citricultura paulista livre do cancro cítrico. É interessante contextualizar essa afirmação ao se levar em conta que o levantamento realizado pelo Fundecitrus em 2012 apontou 1,39\% dos talhos do parque citrícola contaminados com a doença, ou seja, a maior parte absoluta do parque citrícola paulista encontrava-se livre da doença.

Dentre todos os cenários simulados, o valor presente do custo de manejo da doença é maior nas situações em que a doença segue em expansão e apenas um percentual dos talhões é erradicado (subcenários 3B, 3C, 3D, 3E e 3F). Contudo, o custo é inversamente proporcional ao número de talhões erradicados, ou seja, os resultados indicam que para a citricultura paulista, quanto maior for o número de talhões doentes erradicados, menor será o custo de manejo da doença (Tabela 3). Tal relação é observada ao comparar os subcenários 3B, 3C, 3D, 3E e 3F, em que se erradicam $20 \%, 40 \%, 60 \%, 90 \%$ e $95 \%$ dos talhões contaminados, respectivamente. 
Figura 3. Valor presente dos custos com manejo do cancro cítrico, acumulado para 5, 10, 15 e 20 anos de projeção. Em milhões de reais de julho de 2012

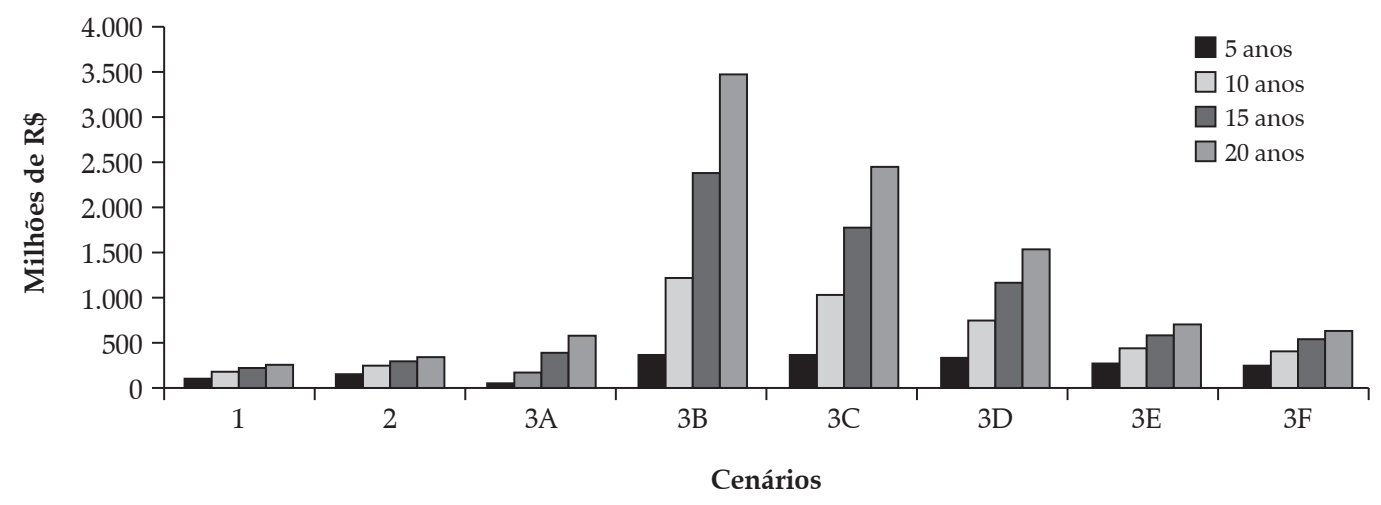

Fonte: Resultados da pesquisa.

Um ponto importante nas situações simuladas, em que um percentual do parque citrícola reduza a taxa de disseminação da doença com inspeção e eliminação de focos, e o restante manejo o cancro cítrico com pulverizações cúpricas, é a questão temporal. Nos subcenários 3B, 3C, $3 \mathrm{D}, 3 \mathrm{E}$ e $3 \mathrm{~F}$ o valor presente dos custos referentes ao manejo do cancro cítrico aumentam de forma acentuada ao longo do tempo. Esse aumento ao longo do tempo é muito inferior ao encontrado nas situações de inspeção e erradicação.

No subcenário 3A, diferente dos outros subcenários 3, simula-se a situação em que o manejo do cancro cítrico é unânime em todo o parque citrícola. Como resultado, os custos de manejo da doença encontrados foram substancialmente inferiores aos dos outros subcenários 3 , mas com a mesma característica de elevação ao longo do tempo. É válido ressaltar que a situação de manejo, simulada no subcenário 3A, é uma situação distante da realidade atual do parque citrícola paulista, dado que mais de $98 \%$ dos talhões paulistas não estavam contaminados pela doença no levantamento realizado em 2012, e esse manejo exigiria uma reestruturação do parque citrícola considerando a ausência de quebra-ventos e talhões com variedades muito suscetíveis à doença. Tais custos adicionais, decorrentes dessa reestruturação, não foram estimados neste trabalho, mas são de grande relevância para uma even- tual implementação desta alternativa avaliada no cenário de manejo sem erradicação de focos.

A partir dos dados obtidos e discutidos acima, ao comparar as diferenças de caixas de laranja produzidas e os respectivos custos de produção, incluindo os custos com manejo da doença, entre os cenários de controle e de prevenção com relação ao cenário doença em expansão, sem controle (Cenário 4), é possível calcular a relação benefício-custo para esses cenários e avaliar a viabilidade econômica da citricultura diante dos mesmos, e estimar os benefícios do manejo da doença.

Ao dividir o diferencial do valor da produção em cada cenário pelo seu respectivo diferencial de custo de manejo, o quociente indica o quanto se deixa de perder com a doença (em produção) ao se gastar R\$1 a mais para seu controle (ou prevenção, conforme o caso estudado no cenário). A Tabela 4 apresenta a relação benefício-custo encontrada nos cenários simulados para o acumulado em 5, 10, 15 e 20 anos, com o preço real da caixa de laranja $(40,8 \mathrm{Kg})$ mantido fixo aos níveis de $R$ \$ 3,30, R\$ 10,50, R\$21,10, em reais de julho de 2012, que são, respectivamente, o valor mínimo, médio e máximo da série de preços reais de laranja sem contrato, para São Paulo, entre 1995 e 2012.

Ao considerar um nível de preço da caixa de laranja maior, a relação benefício-custo aumenta, enquanto que o contrário também é valido, ou 
Tabela 4. Relação benefício-custo calculada pela diferença entre o valor presente da produção e o custo total de produção com diferentes níveis de preço pago pela caixa de laranja. São Paulo, 2011 a 2030

\begin{tabular}{|c|c|c|c|c|c|c|c|c|c|}
\hline $\begin{array}{l}\text { Acumulado } \\
\quad \text { (anos) }\end{array}$ & $\begin{array}{c}\text { Preço da cx } \\
\text { de } 40,8 \mathrm{Kg} \\
\text { (R\$) }\end{array}$ & Cen. 1 & Cen. 2 & Cen. 3A & Cen. 3B & Cen. 3C & Cen. 3D & Cen. 3E & Cen.3F \\
\hline \multirow{3}{*}{5 anos } & 3,3 & 0,48 & 0,25 & 1,18 & 0,00 & $-0,07$ & $-0,09$ & $-0,11$ & $-0,11$ \\
\hline & 10,5 & 1,54 & 0,80 & 3,76 & 0,00 & $-0,21$ & $-0,27$ & $-0,36$ & $-0,34$ \\
\hline & 21,1 & 3,09 & 1,62 & 7,56 & 0,01 & $-0,42$ & $-0,55$ & $-0,71$ & $-0,68$ \\
\hline \multirow{3}{*}{10 anos } & 3,3 & 1,54 & 1,22 & 1,16 & $-0,09$ & $-0,19$ & $-0,08$ & 0,35 & 0,45 \\
\hline & 10,5 & 4,90 & 3,89 & 3,68 & $-0,28$ & $-0,59$ & $-0,24$ & 1,13 & 1,45 \\
\hline & 21,1 & 9,84 & 7,81 & 7,40 & $-0,55$ & $-1,19$ & $-0,49$ & 2,26 & 2,91 \\
\hline \multirow{3}{*}{15 anos } & 3,3 & 2,81 & 2,43 & 1,18 & $-0,18$ & $-0,26$ & 0,03 & 1,18 & 1,36 \\
\hline & 10,5 & 8,94 & 7,74 & 3,76 & $-0,56$ & $-0,84$ & 0,09 & 3,74 & 4,34 \\
\hline & 21,1 & 17,96 & 15,55 & 7,56 & $-1,12$ & $-1,69$ & 0,19 & 7,51 & 8,72 \\
\hline \multirow{3}{*}{20 anos } & 3,3 & 3,84 & 3,34 & 1,19 & $-0,21$ & $-0,24$ & 0,16 & 1,78 & 2,02 \\
\hline & 10,5 & 12,23 & 10,63 & 3,79 & $-0,66$ & $-0,78$ & 0,50 & 5,66 & 6,43 \\
\hline & 21,1 & 24,58 & 21,37 & 7,62 & $-1,33$ & $-1,56$ & 1,01 & 11,38 & 12,92 \\
\hline
\end{tabular}

Fonte: Resultados da pesquisa.

seja, ao considerar um nível mais baixo de preço para a caixa de laranja, a relação benefício-custo diminui. Certamente um preço muito baixo pago pela caixa de laranja pode inviabilizar o controle de pragas, ou mesmo, inviabilizar a produção agrícola. Com o objetivo de avaliar a relação benefício-custo em diferentes níveis de preços pagos ao produtor, considera-se o valor mínimo, médio e máximo da série de preços reais de laranja sem contrato, entre os anos de 1995 e 2012, em São Paulo. Assim, pretende-se indicar a relação benefício-custo para diferentes níveis de preços pagos pela caixa de laranja.

Vale a pena ressaltar que a diferença entre a relação benefício-custo encontrada nos cenários permanece a mesma, independente da variação no preço da caixa, pois segundo as premissas do modelo, a quantidade de caixas produzida é a mesma independente do preço. No modelo adotado, variações no preço influenciam a magnitude do benefício em todos os cenários na mesma proporção (valor da produção), mas, em termos relativos, a diferença no benefício entre os cenários é a mesma. O benefício-custo encontrado evidencia as vantagens em termos relativos, ao comparar cada cenário à situação de não controle (Cenário 4), enfatizando as vantagens de prevenir, controlar e manejar a doença.
Pelas relações benefício-custo obtidas, nota-se que os cenários de prevenção e controle do cancro (Cenários 1 e 2) geram relações positivas e maiores do que um. Isso indica que para cada real investido, os produtores recebem mais do que, proporcionalmente, pelo seu "investimento". Tal resultado implica que o retorno de se evitar a expansão ou contaminação dos pomares compensa seus custos.

Conforme destacam Miranda et al. (2010), o custo de se prevenir ou controlar a disseminação de pragas de relevância econômica para o país pode ser visto como um investimento do setor produtivo ou do governo, tendo em vista que o mesmo visa a garantir a sanidade dos cultivos e a própria proteção do território (e de suas regiões) da introdução ou da disseminação de pragas.

Ainda na Tabela 4, nota-se que, nos subcenários 3B, 3C, 3D e 3F, esta relação, além de inferior a 1 , é negativa. Isso indica que, na comparação entre custos e ganhos, embora os produtores estejam investindo para controlar a doença, têm prejuízos líquidos. Ou seja, a produção obtida não é suficiente para compensar os custos adicionais com a doença, portanto, não compensando economicamente para a citricultura permanecer nesse cenário.

Nota-se que nos subcenários 3D, 3E e 3F a relação passa de negativa no curto prazo (cinco 
anos) para positiva no longo prazo (10, 15 e 20 anos). Verifica-se que a velocidade em que a relação benefício-custo passa de negativa para positiva está diretamente relacionada ao percentual de plantas em que se realiza o controle rigoroso da doença. Ou seja, quanto maior o percentual de plantas sob o controle da doença, menor o tempo necessário para a relação benefício-custo passar de negativa para positiva ao longo do tempo.

Estes resultados evidenciam que há um limite mínimo de erradicação necessário para que se permaneça rentável investir no controle de pragas na citricultura paulista, com parte dos produtores erradicando plantas contaminadas e outros manejando o cancro cítrico. Os resultados indicam que esse limite está próximo dos $80 \%$ de erradicação das plantas doentes, com os restantes $20 \%$ sendo manejados, conforme evidenciado pelos resultados na Tabela 4 .

Nota-se, ainda, que à medida que se estende a percentagem dos talhões doentes que são eliminados (subcenários 3E e $3 \mathrm{~F}$ ), a produção se eleva ao longo dos anos, compensando esta supressão de plantas, e os custos são substancialmente menores comparados às situações em que um percentual menor dos talhões doentes é erradicado (subcenário 3B). Isto porque, além de quanto maior a percentagem de talhões contaminados erradicados, menor a disseminação da doença, considera-se que a produtividade é mantida nas plantas restantes e nas que são replantadas. Consequentemente, o diferencial de produção compensa o diferencial de custos incorridos nestes cenários.

Há que se considerar também que, em função da perda paulatina na produtividade e do tempo necessário para a disseminação da doença, se a análise temporal dos cenários for de curto e médio prazos, a relação benefício-custo é menor, sinalizando que os benefícios de controlar o cancro aumentam no longo prazo.

Os resultados demonstram que no curto prazo o cenário controle apresenta uma relação benefício-custo inferior ao Cenário 3 - doença em expansão, em que os talhões contaminados recebem tratamento químico (subcenário 3A). Porém, no médio e longo prazos, a relação se inverte, de modo que o cenário de controle passa a apresentar uma relação benefício-custo significativamente superior ao subcenário 3A, em especial pelos subcenários 3E e 3F, com alta eliminação de plantas doentes, embora apresente uma relação benefício-custo reduzida no curto prazo, essa relação aumenta significativamente no médio e longo prazos.

Esta constatação contribui para explicar porque há uma dificuldade, constatada no campo, pelos levantamentos mais recentes para o cancro cítrico em São Paulo, de convencer o citricultor a eliminar todas as plantas doentes de seu pomar. Os resultados encontrados demonstram que a relação benefício-custo de prevenir e controlar a doença é maior no médio e longo prazos, e, mais uma vez, isto reforça a ideia de que as medidas de proteção fitossanitária têm natureza de um investimento para a manutenção da produção ao longo do tempo.

\section{Conclusões}

Os diferentes cenários de erradicação e controle testados indicam que em alguns cenários analisados o custo das medidas é de tal magnitude que não haveria compensação econômica suficiente (em termos de produção) para estimular os produtores a adotarem tais medidas. Por outro lado, os resultados apontam que há um ponto ótimo de nível de tratamento (ou controle da expansão da doença) que promove, de fato, benefícios líquidos em comparação a um cenário em que os produtores não controlam a doença.

Os resultados mostram que há evidentes vantagens econômicas, verificadas por uma relação benefício-custo positiva e acima de um, em prevenir a entrada do cancro cítrico em regiões e áreas ainda não contaminadas, principalmente porque, mesmo na ausência da doença, áreas com histórico têm custos de produção elevados pelas medidas preventivas preconizadas.

Considerando que mais de $98 \%$ dos talhões do parque citrícola paulista estavam livres do cancro cítrico em 2012, apesar do aumento acentuado na disseminação da doença desde 2009, a 
situação de prevenção e de controle ainda era a realidade da maior parte do parque citrícola paulista nesse ano. Nesse contexto, as simulações realizadas indicam que a prevenção e erradicação de focos é a melhor estratégia a ser adotada. Em termos de quantidade de laranja produzida ou aumento nos custos de produção, as situações de prevenção e erradicação apresentam vantagens expressivas frente àquelas em que apenas um percentual do parque realiza a erradicação, e o restante opta pelo manejo com a doença.

A questão do horizonte de tempo avaliado mostrou-se fundamental no processo de tomada de decisão em investir na prevenção e controle da doença. A relação benefício-custo de manter o cancro cítrico sob controle apresentou diferença expressiva comparada àquela obtida para o cenário da doença em expansão, quando avaliado no médio e longo prazos.

Enquanto na situação de manejo da doença (subcenário 3A) a relação benefício-custo aumenta apenas $1 \%$ no acumulado de 20 anos, comparado ao acumulado de cinco anos, nos cenários de prevenção e erradicação essa relação aumenta significativamente no médio e longo prazos. No acumulado de 20 anos, essa relação benefício-custo nas situações de prevenção e controle, são respectivamente $695 \%$ e $1.220 \%$ superiores àquela obtida para o cenário acumulado de cinco anos.

Nas situações em que apenas um percentual do parque realiza a inspeção e erradicação, com o restante manejando a doença, o horizonte de tempo se mostrou bastante relevante para a avaliação do custo benefício. Os resultados indicam que quanto maior o percentual do parque que realiza a erradicação da doença, maior é o aumento na relação benefício-custo ao longo dos anos. Nas situações em que $90 \%$ e $95 \%$ do parque citrícola realizam a erradicação, a relação benefício-custo se eleva respectivamente de $1.700 \%$ e $2.000 \%$, no acumulado de 20 anos, comparado ao de cinco anos. Já na situação em que apenas $40 \%$ do parque realiza a erradicação, a relação benefício-custo aumenta $270 \%$ em 20 anos, comparado ao acumulado de cinco anos.

Por um lado, os resultados servem para melhor compreender porque, individualmente e considerando apenas o curto prazo na tomada de decisão, muitos produtores optam por não erradicar as plantas doentes e as plantas vizinhas, mantendo-as no campo, e desta forma contribuindo para o aumento da incidência da doença no estado. Ao se levar em consideração a idade do pomar, a sua produtividade no momento em que se constata a doença, os custos de erradicação e a perda de receita imediata pela erradicação, bem como os custos para tratamentos preventivos, individualmente, produtores obtêm benefícios de curto prazo em ignorar a regulamentação fitossanitária de controle do cancro cítrico.

Contudo, por outro lado, os resultados desta pesquisa demonstram as vantagens econômicas de manter o cancro cítrico sob baixíssimas incidências no estado de São Paulo ao se considerar o médio e longo prazos, demonstrando que a escolha do setor de investir na inspeção e erradicação da doença é tão financeiramente melhor quanto maior for o percentual de plantas que são alvo de medidas preventivas, comparada à situação de manejo integrado da doença.

\section{Referências bibliográficas}

AMARAL, S. F. Providências para a erradicação do cancro cítrico. O Biológico, São Paulo, v .23, p. 112-123, 1957.

BARRETO, M. C., SILVA SILVA, P. C. G., CARVALHO, A. C. A., ALMEIDA, C. O. e WANDER, A. E. (2011) Impactos socioeconômicos da dispersão da mosca-dacarambola (Bactrocera carambolae) à fruticultura naciona, p. 185-195. In SILVA, A. R., LEMOS, W. R. e ZUCCHI, R. A. (Eds.). Moscas-das-frutas na Amazônia Brasileira diversidade, hospedeiros e inimigos naturais, Embrapa Amapá, 299p.

BEHLAU, F., BELASQUE, Jr. J., BERGAMIN FILHO A. e LEITE JR., R. P. Incidência e severidade de cancro cítrico em laranja 'Pêra Rio' sob condições de controle e proteção com quebra-vento. Fitopatologia Brasileira, v. 32, p. 311-317, 2007.

BEHLAU, F., BELASQUE Jr. J., BERGAMIN FILHO A., GRAHAM J. H., LEITE Jr. R. P. e GOTTWALD, T. R. Copper sprays and windbreaks for control of citrus canker on young orange trees in southern Brazil. Crop Protection, v. 27, p. 807-813, 2008. 
BENTO, J. M. S. Comedores de Lucro. Cultivar, v. 22, p. 18-21, 2000.

CALVIN, L. e KRISSOFF, B. Technical Barriers to Trade: A Case Study of Phytosanitary Barriers and U.S.-Japanese Apple Trade. Journal of Agricultural and Resource Economics, v. 23, n. 2, p. 351-66, 1998.

COSTA, C.C. eGUILHOTOJ.J.M. Impactos econômicos do sistema de detecção e eliminação precoce de citros com Huanglonging. Revista de Economia e Agronegócio, v. 9, n. 3, 2013.

FOOD AND AGRICULTURE ORGANIZATION OF UNITED NATIONS. The Statistics Division. FAOSTAT: core production data. Disponível em: <www.faostat. fao.org/site/340/default.aspx>. Acesso em: 5 mai. 2012.

FUNDO DE DEFESA DA CITRICULTURA. Disponível em: <www.fundecitrus.com.br>. Acesso em: 5 maio 2014.

GOTTWALD, T. R., HUGHES, G., GRAHAM, J. H., SUN, X. e RILEY, T. The citrus canker epidemic in Florida: The scientific basis of regulatory eradication policy for an invasive species. Phytopathology, v. 91, p. 30-34, 2001.

GOTTWALD, T. R., SUN, X., RILEY, T., GRAHAM, J. H., FERRANDINO, F. e TAYLOR, E. L. Geo-referenced spatiotemporal analysis of the urban citrus canker epidemic in Florida. Phytopathology, v. 92, p. 361-377, 2002.

HODGES, A. W. e RAHMANI, M. Economic Impacts of the Florida Citrus Industry in 2007/08. Electronic Data Information Source (EDIS) FE802, University of Florida, Gainesville, FL, 2009.

INSTITUTO BRASILEIRO DE GEOGRAFIA E ESTATÍSTICA - IBGE. Sistema IBGE de Recuperação Automática. Disponível em: <http://www.sidra.ibge. gov.br>. Acesso em: 5 mar. 2012.

KOIZUMI, M. Citrus canker: the world situation. In: TIMMER, L. W. (Ed.). Citrus canker: an international perspective. University of Florida/Institute of Food and Agricultural Science, Gainesville, 1985. p. 2-7.

MACLEOD, A The Benefits abd costs of specific phytosanitary campaigns in the UK, p. 163-177. In: New Approaches to the Economics of Plant Health. Netherlands, Springer. 2006

MIRANDA, S. H. G., BASSANEZI, R. B., ADAMI, A. C. O. ABC das ações de defesa fitossanitária para o HLB em São Paulo: lições para a citricultura do Nordeste. Bahia Agrícola, 2011, v. 9, n. 1, p. 64-71.

MIRANDA, S. H. G. e XIMENES, V. P. A importância econômica dos impactos da introdução de pragas exógenas no Brasil. In: Agronegócios. Ed. IBPEX: Curitiba. Capítulo 08, p. 95-106, 2009.
MIRANDA, S. H. G., NASCIMENTO, A. M., XIMENES V. P. e BASSANEZI, R. B. (2010). Uma aplicação da Análise Benefício-Custo para políticas de Defesa Sanitária: alguns estudos de caso para o Brasil. Relatório de Pesquisa (Projeto CNPq n. 505157/2007-1 - "Inovação Tecnológica para Defesa Agropecuária", coordenado por Evaldo Vilella). 110p.

MURARO, R. P. e MALUGEN, J. C. Section VI: Citrus price/return analysis: an examination of investment returns to citrus in a citrus canker and greening environment. In: SPREEN, T. H., BARBER JUNIOR, R. E., BROWN, M. G., HODGES, A. W., MALUGEN, J. C., MULKEY, W. D., MURARO, R. P., NORBERG, R. P., RAHMANI, M., ROKA, F. M. e ROUSE, R. E. An economic assessment of the future prospects for the florida citrus industry, p. 45-55, 2006. Disponível em: $\quad<$ http://www.floridajuice.ifas.ufl.edu/pubs/ EconAssessment.pdf $>$. Acesso em: 20 set. 2011.

NEVES, M. F. (Coord.)., TROMBIN, N. G., MILAN, P., LOPES, F. F., CRESSONI, F. e KALAKI, R. O Retrato da Citricultura brasileira. Centro de pesquisas e marketing e estratégias. Disponível em: <http://www.citrusbr. com.br/> . Acesso em: 10 ago. 2011.

OLIVEIRA C. M., AUAD, A. M., MENDES, S. M. e FRIZZAS, M. R. (2012). Economic impact of exotic insect pests in Brazilian agriculture. Journal of Applied Enthomology doi: 10.1111/jen.12018.

OLIVEIRA, J. M. C. Diaphorina citri Kuwayama, 1908 E Candidatus Liberibacter spp: Associação que coloca em risco a citricultura bahiana: uma estimativa do impacto econômico. 2011-2012. Dissertação de Mestrado. Universidade Federal do Recôncavo Baiano - UFRB, Cruz das Almas. 2012. 118p.

SÃO PAULO (Estado). Resolução da Secretaria de Agricultura e Abastecimento (SAA) no 43, 25 de junho de 2009. Diário Oficial do Estado de São Paulo, 27 de junho de 2009. Seção 1. P. 47.

SÃO PAULO (Estado). Resolução da Secretaria de Agricultura e Abastecimento (SAA) no 147, de 31 de outubro de 2013. Diário Oficial do Estado de São Paulo, 1ํe novembro de 2013, Seção 1. p. 50.

SPREEN, T.H.; MURARO, R.P. Section III: Diseases and other factors affecting Florida citrus production. In: SPREEN, T.H.; BARBER JUNIOR, R.E.; BROWN, M.G.; HODGES, A.W.; MALUGEN, J.C.; MULKEY, W.D.; MURARO, R.P.; NORBERG, R.P.; RAHMANI, M.; ROKA, F.M.; ROUSE; R.E. An economic assessment of the future prospects for the florida citrus industry. p.13-20, 2006. Disponível em: <http://www.floridajuice.ifas.ufl.edu/ pubs/EconAssessment.pdf > . Acesso em: 20 set. 2011. 